\title{
PENGARUH PERPUTARAN MODAL KERJA TERHADAP LIKUIDITAS PERUSAHAAN JASA SUB SEKTOR PROPERTY, REAL ESTATE DAN KONTRUKSI BANGUNAN
}

\author{
Idham Saputra $^{1}$, Andir Indrawan ${ }^{2}$, Ade Sudarma ${ }^{3}$ \\ Universitas Muhammadiyah Sukabumi ${ }^{1,2,3}$ \\ Idhamsaputr4@yahoo.co.id ${ }^{1}$
}

\begin{abstract}
ABSTRAK
Tujuan penelitian ini adalah untuk dapat mengetahui pengaruh perputaran modal kerja terhadap likuiditas (Current Ratio) pada perusahaan Jasa Sub Sektor Property, Real Estate dan Kontruksi. Penelitian ini menggunakan tipe penelitian hipotesis asosiatif. Metode penelitian yang digunakan adalah kuantitatif. Sampel dalam penelitian sebanyak 6 perusahaan Jasa Sub Sektor Property, Real Estate dan Kontruksi yang terdaftar di Bursa Efek Indonesia periode 2013-2018. Pengambilan sampel dengan jenis nonprobability sampling dengan teknik purposive sampling. Teknik analisis data yang digunakan uji normalitas dan uji hipotesis parsial (uji t). Hasil penelitian, dari hasil uji hipotesis parsial (uji t) dapat dilihat nilai thitung dari variabel perputaran modal kerja (X) sebesar -3.735 dengan tingkat signifikan 0,001, artinya perputaran modal kerja berpengaruh negatif terhadap likuiditas dan nilai signifikan menunjukan pengaruh yang signifikan. Simpulan, perputaran modal kerja berpengaruh negatif terhadap likuiditas hal ini karena pendapatan yang tidak menentu. Semakin tinggi nilai likuiditas maka semakin tinggi nilai aktiva lancar yang juga akan berbanding lurus dengan hasil penjualannya. Perputaran modal kerja tidak selalu berbanding lurus dengan likuiditasnya.
\end{abstract}

Kata Kunci: Likuiditas, Perputaran Modal Kerja, Perputaran Piutang

\section{ABSTRACT}

The purpose of this study was to determine the effect of working capital turnover on liquidity (Current Ratio) in the Property, Real Estate and Construction Sub Sector Services company. This research uses associative hypothesis research type. The research method used is quantitative. The sample in this study were 6 Property, Real Estate and Construction Sub Sector Services companies listed on the Indonesia Stock Exchange in the 2013-2018 period. Sampling with the type of nonprobability sampling with purposive sampling technique. The data analysis technique used is the normality test and the partial hypothesis test ( $t$ test). The results of the research, the partial hypothesis test results ( $t$ test) can be seen the $t$-count of the variable working capital turnover $(X)$ of $-3,735$ with a significant level of 0.001, meaning that the working capital turnover has a negative effect on liquidity and the significant value shows a significant effect. In conclusion, working capital turnover has a negative effect on liquidity because of uncertain income. The higher the liquidity value, the higher the value of current assets which will also be directly proportional to the sales results. Working capital turnover is not always directly proportional to liquidity.

Keywords: Working Capital Turnover, Accounts Receivable Turnover, Liquidity. 


\section{PENDAHULUAN}

Perekonomian Indonesia pada saat ini sedang menuju pada era globalisasi pada dasarnya setiap perusahaan akan selalu mengembangkan atau berinovasi pada produk yang dijalankannya, baik itu perusahaan yang bergerak dalam bidang manufaktur ataupun jasa, agar mampu bertahan dan terus maju dalam persaingan usaha.Untuk mencapai tujuannya perusahaan harus dilakukan penilaian terhadap kinerja keuangan perusahaan, yaitu dengan menganalisa laporan keuangan melalui rasio likuiditas.

Tujuan utama dari adanya perusahaan adalah untuk menghasilkan laba. Dalam kegiatan operasionalnya untuk mencari laba tersebut tentu mempunyai risiko yang dapat menghambat pemenuhan kewajiban jangka pendek perusahaan. Sehingga mengganggu aktivitas perusahaan. Fahmi, (2014) menjelaskan masalah yang timbul didalam penurunan likuiditas diantaranya akibat jumlah asset lancar yang yang cenderung lebih kecil dari jumlah likuiditas lancar pada suatu perusahaan.

Selain itu perusahaan juga perlu menghitung perputaran modal kerja untuk dapat mengetahui seberapa besar pengaruh perputaran modal kerja terhadap likuiditas (Current Ratio). Hal ini dilakukan agar dapat mengantisipasi kerugian yang mengakibatkan turunnya likuiditas (Sutrisno, 2012).

Modal kerja merupakan asset paling likuid karena dapat digunakan untuk membayar kewajiban perusahaan. Keberadaan modal kerja dalam entitas sangat penting, karena tanpa adanya modal aktivitas perusahaan tidak dapat terpenuhi. Entitas harus dapat menjaga modal agar sesuai dengan kebutuhannya. Jika jumlah modal kerja kurang maka kegiatan operasional perusahaan dapat terganggu. Kemudian jika modal keraja berlebihan akan menunjukan terdapat dana tidak produktif dalam perusahaan.

Keefektifan modal kerja dapat dilihat melalui perputaran modal kerja atau Net Working Capital dengan melihat seberapa banyak modal kerja berputar selama suatu periode atau dalam satu periode. Kasmir (2015) menjelaskan hal ini dimulainya pada saat dana di investasikan kedalam unsur-unsur modal kerja sampai masuk kembali menjadi kas berikutnya.

Berdasarkan latar belakang diatas maka penulis tertarik melakukan maka penelitian lebih lanjut tentang perputaran modal kerja terhadap likuiditas menggunakan 
rasio lancar (Current Ratio) pada peusahaan Jasa Sub Sektor Property, Real Estate dan Kontruksi Bangunan yang terdaftar di Bursa Efek Indonesia pada periode 2013-2018.

Tujuan penelitian ini adalah untuk mengetahui pengaruh perputaran modal kerja terhadap likuiditas (Current Ratio) pada perusahaan Jasa Sub Sektor Property, Real Estate dan Kontruksi yang terdaftar di Bursa Efek Indonesia pada periode 2013-2018.

\section{KAJIAN TEORI}

\section{Modal Kerja}

Modal kerja di definiskan sebagai suatu modal yang dapat digunakan dalam membiyai dan memenuhi kebutuhan operasional perusahaan, terutama dalam waktu jangka pendek. Suatu perusahaan yang tidak mempunyai modal yang cukup, maka tidak akan dapat membayar kewajiban jangka pendek secara tepat waktu dan pada akhirnya akan berhadapan dengan masalah likuiditas (Curent Ratio). Investasi modal kerja merupakan suatu proses terus-menerus selama perusahaan berjalan. Menurut Riyanto, (2010) modal kerja di bagi menjadi tiga konsep:1) Konsep Kuantitatif, sering dikatakan sebagai Gross Working Capital yang mana dapat menggambarkan dari keseluruhan jumlah dari aktiva lancar, dimana aktiva lancar ini merupakan aktiva sekali berputar dan akan kembali kebentuk semula atau aktiva dimana dana yang telah tertanam di dalamnya akan dapat bebas lagi dalam jangka waktu yang pendek. Sehingga dengan demikian modal kerja menurut konsep kuantitatif ini adalah keseluruhan dari aktiva lancar atau modal kerja bruto (Gross Working Capital); 2) Konsep Kualitatif, yaitu selisih aktiva lancar yang dimiliki perusahaan dengan hutang lancar, atau merupakan dari bagian aktiva lancar yang dapat digunakan dalam membiyai operasi perusahaan tanpa harus menunggu likuiditasnya. Yaitu merupakan kelebihan dari aktiva lancar di atas utang lancarnya. Maka dari itu modal kerja dalam pengertian ini sering dikatakan modal kerja netto atau modal kerja (Net Working Capital); 3) Konsep Fungsional, merupakan konsep yang didasarkan pada fungsi dari dana dalam menghasilkan pendapatan. Setiap dana yang digunakan dalam suatu periode akuntansi tertentu dapat langsung menghasilkan pendapatan bagi periode tersebut (Current Income), artinya sejumlah dana yang dimiliki dan digunakan perusahaan untuk meningkatkan laba perusahaan. Semakin banyak dana yang digunakan sebagai modal kerja maka 
seharusnya dapat meningkatkan pendapatan laba demikian pula sebaliknya, jika dana yang digunakan sedikit, laba yang akan di dapatkan oleh perusahaan pun akan menurun.

\section{Jenis-Jenis Modal Kerja}

Riyanto (2013) menjelaskan ada 2 jenis modal kerja yaitu; Modal kerja Permanen (Permanent Working Capital) yaitu modal kerja yang harus tetap ada pada perusahaan untuk dapat menjalankan fungsinya.atau dengan kata lain modal kerja yang secara terus menerus diperlukan untuk kelancaran usaha dan Modal kerja Normal (Variabel Working Capital) yaitu modal kerja yang jumlahnya berubah-rubah sesuai dengan keadaan.

\section{Faktor-faktor yang mempengaruhi modal kerja}

Kasmir (2015) mengatakan jika modal kerja yang dibutuhkan perusahaan harus segera terpenuhi sesuai dengan kebutuhan perusahaan. Namun, terkadang untuk memenuhi kebutuhan modal kerja seperti yang diinginkan tidaklah selalu tersedia. Hal ini disebabkan terpenuhi tidaknya kebutuhan modal kerja sangat tergantung kepada berbagai faktor yang mempengaruhinya. Oleh karena itu, pihak manajemen dalam menjalankan kegiatan operasi perusahaan terutama kebijakan dalam upaya pemenuhan modal kerja harus selalu memperhatikan beberapa faktor, diantaranya yaitu sebagai berikut:

Jenis Perusahaan

Jenis perusahaan di bagi kepada dua bagian yaitu: Perusahaan yang bergerak dalam bidang jasa dan non jasa (industri). Kebutuhan modal dalam perusahaan industry lebih besar jika dibandingkan dengan perusahaan jasa. Diperusahaan industry, investasi dalam bidang kas, piutang, dan sediaan relatip lebih besar jika dibandingkan dengan perusahaan jasa.

Syarat Kredit

Syarat kredit yaitu yang dapat dilakukan dengan cara mencicil (angsuran) juga sangat mempengaruhi modal kerja. Untuk meningkatkan penjualan bias dilakukan dengan berbagai cara dan salah satunya adalah melalui penjualan secara kredit. Penjualan barang secara kredit memberikan kelonggaran kepada konsumen untuk 
membeli barang dengan cara pembayaran diangsur (dicicil) beberapa kali untuk jangka waktu tertentu.

\section{Waktu Produksi}

Untuk waktu produksi, yang mana artinya jangka waktu atau lamanya memperoduksi suatu barang. Makin lama waktu yang digunakan untuk memproduksi suatu barang, maka akan semakin besar modal kerja yang dibutuhkan. Demikian pula sebaliknya semakin pendek waktu yang dibutuhkan untuk memproduksi suatu barang, maka semakin kecil modal kerja yang dibutuhkan.

Tingkat Perputaran Persediaan

Pengaruh tingakt perputaran persediaan terhadap modal kerja cukup penting bagi perusahaan. Semakin kecil atau rendah tingkat perputaran, kebutuhan modal kerja semakin tinggi, demikian pula sebaliknya. Dengan demikian, dibutuhkan perputaran persediaan yang cukup tinggi agar memperkecil risiko kerugian akibat penurunan harga seta mampu menghemat biaya penyimpanan dan pemeliharaan persediaan.

\section{Perputaran Modal Kerja}

Keefektifan modal kerja dapat digunakan dengan perhitungan perputaran modal kerja (Net Working Capital) yang bertujuan untuk mengetahui perkembangan modal yang dimiliki perusahaan. Riyanto, (2010) untuk mengukur perputaran modal kerja kita membandingkan antara penjualan dengan modal kerja.

\begin{tabular}{|lc|}
\hline Perputaran & Penjualan \\
\cline { 2 - 2 } Modal Kerja $=$ & $\begin{array}{c}\text { Aktivalancar- } \\
\text { Hutang Lancar }\end{array}$ \\
\hline
\end{tabular}

\section{Likuiditas}

\section{Pengertian Likuiditas}

Menurut Fahmi, (2016) likuiditas yaitu kemampua suatu perusahaan memenuhi kewajiban jangka pendeknya secara tepat waktu. Perusahaan dapat menghitung menggunakan rasio likuiditas (Current Ratio) dengan cara membandingkan komponen yang tersedia dalam laporan keuangan (aktiva lancar, perputaran modal kerja dan 
perputaran piutang) dimana komponen-komponen tersebut dapat berpengaruh terhadap likuiditas.

\section{Jenis-Jenis Likuiditas}

Jenis-Jenis rasio yang dapat digunakan yang dikemukakan oleh Kasmir, (2015) diantaranya yaitu:

\section{Rasio lancar (Current Ratio)}

Rasio lancar atau (Current Ratio) merupakan rasio untuk mengukur kemampuan perusahaan dalam membayar kewajiban jangka pendek atau utang yang segera jatuh tempo pada saat ditagih secara keseluruhan.maka dari itu rasio likuiditas yaitu suatu alat pengukur untuk mengetahui suatu perusahaan dalam memenuhi kewajiban jangka pendeknya salah satu cara untuk mengukur rasio likuiditas (Current Ratio) yaitu dengan cara membandingkan antara aktiva lancar dengan liabilitas lancar (Kasmir, 2015) Maka dari itu cara untuk mengukurnya sebagai berikut:

$$
\begin{gathered}
\text { Current } \\
\text { Ratio }
\end{gathered}=\frac{\begin{array}{c}
\text { Aktiva Lancar } \\
\text { (Current Assets) }
\end{array}}{\begin{array}{c}
\text { Utang Lancar } \\
\text { (Current Liabilities) }
\end{array}}
$$

\section{Rasio Cepat (Quick Ratio)}

Rasio cepat (Quick Ratio) atau rasio sangat lancar atau Acid Test ratio merupakan rasio yang menunjukkan kemampuan perusahaan dalam memenuhi atau membayar kewajiban atau utang lancar (utang jangka pendek) dengan aktiva lancar tanpa memperhitungkan nilai sediaan (Inventory). Artinya nilai perdiaan kita abaikan, dengan cara dikurangi dari nilai total aktiva lancar (Kasmir, 2015), maka dari itu untuk mengukur Quick Ratio dapat digunakan dengan rumus sebagi berikut:

$$
\begin{gathered}
\text { Quick } \\
\text { Ratio }
\end{gathered}=\frac{\begin{array}{c}
\text { Current Assets- } \\
\text { Inventory }
\end{array}}{\text { Current Liabilities }}
$$

\section{Rasio Kas (Cash Ratio)}

Rasio kas atau cash ratio merupakan alat yang digunakan untuk mengukur seberapa besar uang kas yang tersedia untuk membaayar utang. Keter sediaan uang kas dapat ditunjukkan dari tersedianya dana kas atau yang setara dengan kas seperti 
rekening giro atau tabungan di bank (yang dapat ditarik setiap saat). Dapat dikatakan rasio ini menunjukan kemampuan sesungguhnya bagi perusahaan untuk membayar utang-utang jangka pendeknya (Kasmir, 2015) Maka rumus yang dapat digunkan untuk mengukur rasio kas yang dapat digunkan sebagai berikut:

$$
\text { Cash }=\frac{\text { Kas }+ \text { Bank }}{\text { Current Liabilities }}
$$

Rasio Perputaran Kas

Menurut James $O$. Gill dalam Kasmir, (2015) mengatakan rasio perputaran kas (Cash Turn Over) berfungsi untuk mengukur tingkat kecukupan modal kerja perusahaan yang dibutuhkan untuk membayar tagihan dan membiyai penjualan. Artinya rasio ini digunkan untuk mengukur tingkat ketersediaan kas untuk membayar tagihan (utang) dan biaya-biaya yang berkaitan dengan penjualan (Kasmir, 2015), maka rumus untuk mencari rasio lancar atau current ratio dapat digunkan sebagai berikut:

$$
\begin{array}{|cc|}
\text { Perputaran } \\
\text { kas }
\end{array}=\begin{gathered}
\begin{array}{c}
\text { Penjualan } \\
\text { bersih }
\end{array} \\
\text { Rata-rata } \\
\text { Kas }
\end{gathered}
$$

\section{Inventory to Net Working Capital}

Inventory to net working capital merupakan rasio yang digunakan untuk mengukur atau membandingkan antara jumlah persediaan yang ada dengan modal kerja perusahaan. Modal kerja tersebut terdiri dari pengurangan antara aktiva lancar dengan utang lancar. Kasmir, (2015) Rumus untuk mencari Inventory To Net Working Capital dapat digunakan sebagai berikut:

$$
\begin{gathered}
\text { Inventory } \\
\text { to NWC }
\end{gathered}=\begin{gathered}
\text { Inventory } \\
\text { Current Assets- } \\
\text { Current Liabilities }
\end{gathered}
$$

Berdasarkan pemaparan yang telah di paparkan diatas maka penulis menyimpulkan bahwa perputaran modal kerja akan dapat memperngaruhi likuiditas yang mana ketika perputaran modal kerja yang tinggi akan dapat meningkatkan pendapatan aktiva lancar sehingga nantinya akan dapat digunakan untuk membayar utang jangka pendek atau likuiditas perusahaan. Maka dari itu likuiditas rasio yang 
digunakan adalah likuiditas (Current Ratio) dimana kemampuan perusahaan dalam mengukur untuk membayar kewajiban jangka pendeknya dapat terpenuhi secara tepat waktu.

\section{METODE PENELITIAN}

Penelitian ini menggunakan tipe penelitian hipotesis asosiatif. Jenis penelitian yang digunakan adalah kuantitatif. Adapun populasi dalam penelitian ini adalah 16 perusahaan Jasa Sub Sektor Property, Real Estate dan Kontruksi Bangunan yang terdaftar di Bursa Efek Indonesia, dengan sampel berjumlah 6 perusahaan yaitu PT Acset Indonusa Tbk, PT Surya Semesta Internusa Tbk, PT Nusa Raya Cipta Tbk, PT Pembangunan Perumahan (persero) Tbk, PT Total Bangun Persabda Tbk, dan PT Wijaya Karya (Persero) Tbk. Teknik pengambilan sampel yang digunakan oleh peneliti adalah nonprobability sampling dengan teknik purposive sampling. Penelitian menggunakan Uji Normalitas data dan Uji Hipotesis Parsial (Uji t).

Variabel dalam penelitian terdiri dari variabel independen yaitu Perputaran modal kerja (X) serta variabel dependen yaitu likuiditas (Y) penelitian ini menggunakan tipe penelitian hipotesis asosiatif dengan pendekatan kuantitatif. Teknik pengumpulan data yang digunakan dalam penelitian ini yaitu menggunakan data sekunder.

Gambar 1.1

Paradigma Penelitian

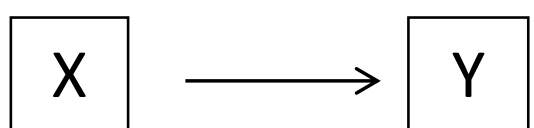

\section{Keterangan:}

Variabel $\mathbf{X}=$ Perputaran Modal Kerja

Variabel $\mathbf{Y}=$ Likuiditas (Current Ratio).

\section{HASIL PENELITIAN}

\section{Hasil Uji Normalitas Data}

Analisis ini menggunakan uji statistic One-Sample Kolmogrov Smirmov Test untuk menguji hasil normal data dengan kriteria pengujian $\alpha 0,05$ sebagai berikut:

a. Jika sig $>\alpha$ berarti data sampel yang diambil terdistribusi normal.

b. Jika sig $<\alpha$ berarti data sampel yang diambil tidak terdistribusi normal. 
Berdasarkan table 1. di bawah ini hasil uji One-Sample Kolomogrov Smirnov Test diatas dapat diketahui nilai Asymp.sig tiap-tiap variable yang diteliti yaitu untuk perputaran modal kerja adalah 0,200 dan untuk likuiditas (Current Ratio) adalah 0,200 yang berarti bahwa variable modal kerja dan likuiditas (Current Ratio) berdistribusi secara normal karena memiliki tingkat signifikan 0,200>0,05.

Tabel 1.

Uji Normalitas

\begin{tabular}{|c|c|c|c|}
\hline \multicolumn{4}{|c|}{ One-Sample Kolmogorov-Smirnov Test } \\
\hline & & Likuiditas & Perputaran \\
\hline & & (Current Ratio) & Modal Kerja \\
\hline $\mathrm{N}$ & & 36 & \\
\hline \multirow{2}{*}{ Normal Parameters ${ }^{\mathrm{a}, \mathrm{b}}$} & Mean & 1.5217 & 5.0147 \\
\hline & Std. Deviation & .2 .6061 & 1.36114 \\
\hline \multirow{2}{*}{ Most Extreme } & Absolute & .081 & .097 \\
\hline & Positive & .081 & .072 \\
\hline Differences & Negative & -.061 & -.097 \\
\hline \multicolumn{2}{|c|}{ Kolmogorov-Smirnov Z } & .081 & .113 \\
\hline \multicolumn{2}{|l|}{ Asymp. Sig. (2-tailed) } & $.200^{\mathrm{c}, \mathrm{d}}$ & $.200^{\mathrm{c}, \mathrm{d}}$ \\
\hline \multicolumn{4}{|c|}{ a. Test distribution is Normal. } \\
\hline \multicolumn{4}{|l|}{ b. Calculated from data. } \\
\hline \multicolumn{4}{|c|}{ c. Lilliefors Significance Correction. } \\
\hline
\end{tabular}

\section{Hasil Uji Hipotesis Parsial (Uji t)}

Kriteria pengujian hipotesis dengan uji t adalah sebagai berikut:

Tabel 2.

Uji Parsial (t) Perputaran Modal Kerja (X1)

\begin{tabular}{|c|c|c|c|c|c|c|}
\hline \multicolumn{7}{|c|}{ Coefficients $^{\mathrm{a}}$} \\
\hline & \multirow[t]{2}{*}{ Model } & & $\begin{array}{l}\text { ndardized } \\
\text { fficients }\end{array}$ & $\begin{array}{r}\text { Standardized } \\
\text { Coefficients } \\
\end{array}$ & \multirow[t]{2}{*}{$\mathrm{T}$} & \multirow[t]{2}{*}{ Sig. } \\
\hline & & $\mathrm{B}$ & Std. Error & Beta & & \\
\hline \multirow{2}{*}{1} & (Constant) & $\begin{array}{l}1.4 \\
75 \\
\end{array}$ & .147 & & $\begin{array}{c}10.02 \\
2\end{array}$ & .000 \\
\hline & $\begin{array}{l}\text { PERPUTARAN } \\
\text { MODAL KERJA } \\
\end{array}$ & $\begin{array}{c}- \\
.047\end{array}$ & .013 & -.538 & -3.735 & .001 \\
\hline \multicolumn{7}{|c|}{ a. Dependent Variable: Likuiditas } \\
\hline
\end{tabular}


Berdasarkan 2 hasil uji t diatas menunjukan bahwa thitung dari variable perputaran modal kerja (X1) sebesar -3.735 dengan tingkat signifikan 0,001. Nilai thitung -3.735 > table 2,036, dapat diartikan bahwa Ha diterima dan Ho ditolak, artinya perputaran modal kerja berpengaruh negatif terhadap likuiditas (Current Ratio) perusahaan dan tingkat signifikan $0,001<0,05$, menunjukan adanya pengaruh negatif yang signifikan antara perputaran modal kerja terhadap likuiditas ekonomi secara parsial pada perusahaan Jasa Sub Sektor Property, Real Estate dan Kontruksi Bangunan yang terdaftar di BEI periode 2013-2018.

\section{PEMBAHASAN}

Berdasarkan hasil pengujian diatas menunjukan bahwa thitung dari variabel perputaran modal kerja (X1) sebesar -3.735 dengan tingkat signifikan 0,001. Nilai thitung -3.735 > tabel 2,036, dapat diartikan bahwa ha diterima dan Ho ditolak, artinya perputaran modal kerja berpengaruh terhadap likuiditas (Current Ratio) perusahaan dan nilai signifikan $0,001<0,05$, menunjukan pengaruh yang signifikan. Maka dapat disimpulkan bahwa perputaran modal kerja berpengaruh negatif terhadap likuiditas (Current Ratio) pada perusahaan Jasa Sub Sektor Property, Real Estate dan Kontruksi Bangunan yang terdaftar di BEI periode 2013-2018.

Menurut Kasmir (2015) tentang likuiditas current ratio bahawa nilai aktiva lancar berbanding terbalik dengan utang lancar. Semakintinggi nilai likuiditas maka semakin tinggi nilai aktiva lancar yang juga akan berbanding lurus dengan hasil penjualannya. Sehingga penjualan yang tinggi akan menunjukan nilai perputaran modal kerja yang tinggi atau dengan kata lain bahwa nilai likuiditas akan berbanding lurus dengan perputaran modal kerjanya namun, pada kenyataannya adanya modal yang tinggi tidak selalu memberikan hasil penjualan yang tinggi. Sehingga perputaran modal kerja tidak selalu berbanding lurus dengan likuiditasnya.

\section{SIMPULAN}

Berdasarkan dari hasil analisis yang telah dilakukan pada 6 perusahaan sub sektor Property, Real Estate dan Kontruksi Bangunan yang terdaftar di BEI periode 2013-2018 mengenai pada perputaran modal kerja terhadap likuiditas (Current Ratio) perusahaan, dapat disimpulkan bahwa perputaran modal kerja berpengaruh negatif 
terhadap likuiditas (Current Ratio). Karena adanya aspek-aspek tertentu dalam perputaran modal kerja yang juga mempengaruhi nilai likuiditas, seperti jenis perusahaan, syarat kredit, waktu produksi, dan tingkat perputaran persediaan.

\section{DAFTAR PUSTAKA}

Fahmi, I. ( 2011). Analisis Laporan Keuangan. Bandung: Alfabeta.

Kasmir. (2015). Analisis Laporan Keuangan. Jakarta: PT. Raja Grafindo Persabda.Laporan Keuangan dan Tahunan. (n.d.). Retrieved from IDX: https://www.idx.co.id/perusahaan-tercatat/laporan-keuangan-dan-tahunan/

Riyanto, B. (2010). Dasar-Dasar Pembelanjaan Perusahaan. Yogyakarta: BPFE.

Sutrisno. (2012). Manajemen Keuangan. Yogyakarta: Kampus Fakultas Ekonomi UII. 